\title{
RNA mutagenesis yields highly diverse mRNA libraries for in vitro protein evolution
}

\author{
George Kopsidas*1, Rachael K Carman ${ }^{1}$, Emma L Stutt ${ }^{1}$, Anna Raicevic ${ }^{2}$, \\ Anthony S Roberts ${ }^{1}$, Mary-Anne V Siomos ${ }^{1}$, Nada Dobric ${ }^{1}$, Luisa Pontes- \\ Braz $^{2}$ and Greg Coia ${ }^{2}$
}

Address: ${ }^{1}$ EvoGenix Ltd., 343 Royal Parade, Parkville, Melbourne 3052, Australia and ${ }^{2}$ CSIRO, Molecular and Health Technologies, 343 Royal Parade, Parkville, Melbourne 3052, Australia

Email: George Kopsidas* - g.kopsidas@evogenix.com.au; Rachael K Carman - r.carman@evogenix.com.au;

Emma L Stutt - e.stutt@evogenix.com.au; Anna Raicevic - anna.raicevic@csiro.au; Anthony S Roberts - a.roberts@evogenix.com.au; MaryAnne V Siomos - m.siomos@evogenix.com.au; Nada Dobric -n.dobric@evogenix.com.au; Luisa Pontes-Braz - luisa.pontes-braz@csiro.au; Greg Coia - greg.coia@csiro.au

* Corresponding author

Published: II April 2007

BMC Biotechnology 2007, 7:18 doi:10.1186/1472-6750-7-18

This article is available from: http://www.biomedcentral.com/1472-6750/7//8

(c) 2007 Kopsidas et al; licensee BioMed Central Ltd.

This is an Open Access article distributed under the terms of the Creative Commons Attribution License (http://creativecommons.org/licenses/by/2.0), which permits unrestricted use, distribution, and reproduction in any medium, provided the original work is properly cited.

\begin{abstract}
Background: In protein drug development, in vitro molecular optimization or protein maturation can be used to modify protein properties. One basic approach to protein maturation is the introduction of random DNA mutations into the target gene sequence to produce a library of variants that can be screened for the preferred protein properties. Unfortunately, the capability of this approach has been restricted by deficiencies in the methods currently available for random DNA mutagenesis and library generation. Current DNA based methodologies generally suffer from nucleotide substitution bias that preferentially mutate particular base pairs or show significant bias with respect to transitions or transversions. In this report, we describe a novel RNAbased random mutagenesis strategy that utilizes $Q \beta$ replicase to manufacture complex mRNA libraries with a mutational spectrum that is close to the ideal.
\end{abstract}

Results: We show that $\mathrm{Q} \beta$ replicase generates all possible base substitutions with an equivalent preference for mutating $A / T$ or $G / C$ bases and with no significant bias for transitions over transversions. To demonstrate the high diversity that can be sampled from a $\mathrm{Q} \beta$ replicase-generated mRNA library, the approach was used to evolve the binding affinity of a single domain $\mathrm{V}_{\mathrm{NAR}}$ shark antibody fragment (I2Y-2) against malarial apical membrane antigen-I (AMA-I) via ribosome display. The binding constant $\left(K_{D}\right)$ of I2Y-2 was increased by 22 -fold following two consecutive but discrete rounds of mutagenesis and selection. The mutagenesis method was also used to alter the substrate specificity of $\beta$-lactamase which does not significantly hydrolyse the antibiotic cefotaxime. Two cycles of RNA mutagenesis and selection on increasing concentrations of cefotaxime resulted in mutants with a minimum 10,000-fold increase in resistance, an outcome achieved faster and with fewer overall mutations than in comparable studies using other mutagenesis strategies.

Conclusion: The RNA based approach outlined here is rapid and simple to perform and generates large, highly diverse populations of proteins, each differing by only one or two amino acids from the parent protein. The practical implications of our results are that suitable improved protein candidates can be recovered from in vitro protein evolution approaches using significantly fewer rounds of mutagenesis and selection, and with little or no collateral damage to the protein or its mRNA. 


\section{Background}

There is a growing demand by the pharmaceutical and medical industries for protein molecules, including antibodies, of diagnostic and therapeutic efficacy, as well as a perpetual need in the production and manufacturing industries for improved biocatalysts. These demands have directed the innovation of a number of sophisticated and complex methods for the in vitro evolution and optimization of proteins [1]. One fundamental approach to this process is the introduction of random mutations into a known nucleotide sequence to produce a library of variants. These variants are subsequently translated to produce modified proteins that are accordingly screened for chosen properties.

The potential of this approach has been limited by deficiencies in the methods currently available for random mutagenesis and library generation [2]. Current methods exclusively target DNA, and include error-prone PCR (EPPCR) [3], the incorporation of triphosphate derivatives of nucleoside analogues with Taq or other DNA polymerases [4] and novel error-prone DNA polymerases or polymerase blends $[5,6]$. Unfortunately, DNA-based mutagenesis systems generally suffer from a nucleotide incorporation bias that favors transitions over transversions and/or results in a skewed preference for mutations at either $\mathrm{A} / \mathrm{T}$ or G/C pairs $[7,8]$. Without doubt, base substitution bias will diverge the distribution of mutations from a Poisson distribution, effectively diminishing the functional size of a randomly mutated gene library available for subsequent screening [9]. In essence, any nucleotide bias reduces the probability for generating specific amino acid substitutions that may be required at key positions along the protein, dramatically reducing the potential for recovering protein variants with a desired set of properties. Directed protein evolution using powerful selection strategies such as ribosome display (described below) are more likely to identify improved variants when a library is maximally diverse which would be the case when all variants in a library are equally probable [10].

We have exploited $\mathrm{Q} \beta$ bacteriophage RNA replicase, an error-prone RNA-dependent RNA polymerase, and its ability to amplify and mutate RNA very rapidly, to develop an in vitro mutagenesis strategy targeting mRNA. We have found that base substitutions at the RNA level are made with very little bias for the incorporation of particular bases, approaching what can be considered as ideal random mutagenesis. The result is the generation of random mRNA libraries carrying very high diversity.

To verify that $Q \beta$ replicase manufactured variant mRNA libraries can be highly effective tools for in vitro protein evolution, two basic demonstrations are presented here. First, $Q \beta$ replicase mutagenesis in combination with a simple functional assay was used to alter the substrate specificity of $\beta$-lactamase for the antibiotic cefotaxime. And second, $\mathrm{Q} \beta$ mRNA mutagenesis coupled to ribosome display was used to enhance the affinity of a single domain antibody fragment $\left(\mathrm{V}_{\mathrm{NAR}}\right)$ to its antigen. Ribosome display is an in vitro display and selection strategy that couples the newly translated protein to the ribosome complex, which in turn, remains tethered to the mRNA message due to the absence of a stop codon on the mRNA (effectively linking phenotype to genotype). An mRNA library can be translated in vitro and the ribosome-proteinmRNA complexes can be subsequently screened (panned) for binding towards the appropriate molecule and nonspecific or weaker binding complexes removed by extensive washing. $[11,12]$. The mRNA is eluted from the remaining (bound) ribosome complexes and amplified with RT-PCR. Ribosome display, in particular, is ideal for the effective screening of large mRNA libraries, with the number of variants that can be screened limited only by the total number of ribosomes in solution (estimated to be up to $10^{14} / \mathrm{ml}$ typically found with in vitro eukaryotic reticulocyte lysate systems) and the total amount of mRNA that can be added to the translation mix [13].

\section{Results \\ Constructing the $\mathrm{Q} \beta$ replicase mutagenesis and ribosome display vectors}

Developing a vector that would allow for the routine application of $\mathrm{Q} \beta$ replicase for the amplification of target mRNA that could also subsequently be used directly in ribosome display was not straightforward. As $\mathrm{Q} \beta$ phage has a double-stranded RNA genome, Q $\beta$ replicase has a strong bias for replicating its own genome with both RNA $(-)$ and $(+)$ strands serving as templates $[14,15]$. To adapt this stringent template preference and allow replication of foreign RNAs, pEGX216, a universal mutagenesis vector (Figure 1A) was constructed based around a small multicloning site (MCS) inserted into a modified RQ $135_{-1}(-)$ sequence. The RQ $135_{-1}(-)$ sequence is the result of a spontaneous recombination of E. coli $23 \mathrm{~S}$ RNA and the phage $\lambda$ origin of replication with the resulting sequence efficiently recognized and amplified by $Q \beta$-replicase [16$18]$. The integrated MCS did not appear to perturb the secondary structure required by $\mathrm{Q} \beta$-replicase to recognize the RNA template. An upstream T7 RNA polymerase promoter sequence on pEGX216 was used to synthesize RNA suitable for $\mathrm{Q} \beta$-replicase.

For the coupling of mutagenesis to ribosome display, pEGX216 was modified to generate a dual purpose mutagenesis/ribosome display vector (pEGX253) by adding various elements required for efficient translation and for tethering the mRNA to the ribosome complex (see methods and Figure 1A). The mRNA transcribed from this vector was subsequently mutated with $\mathrm{Q} \beta$ replicase, heat 


\section{(A)}

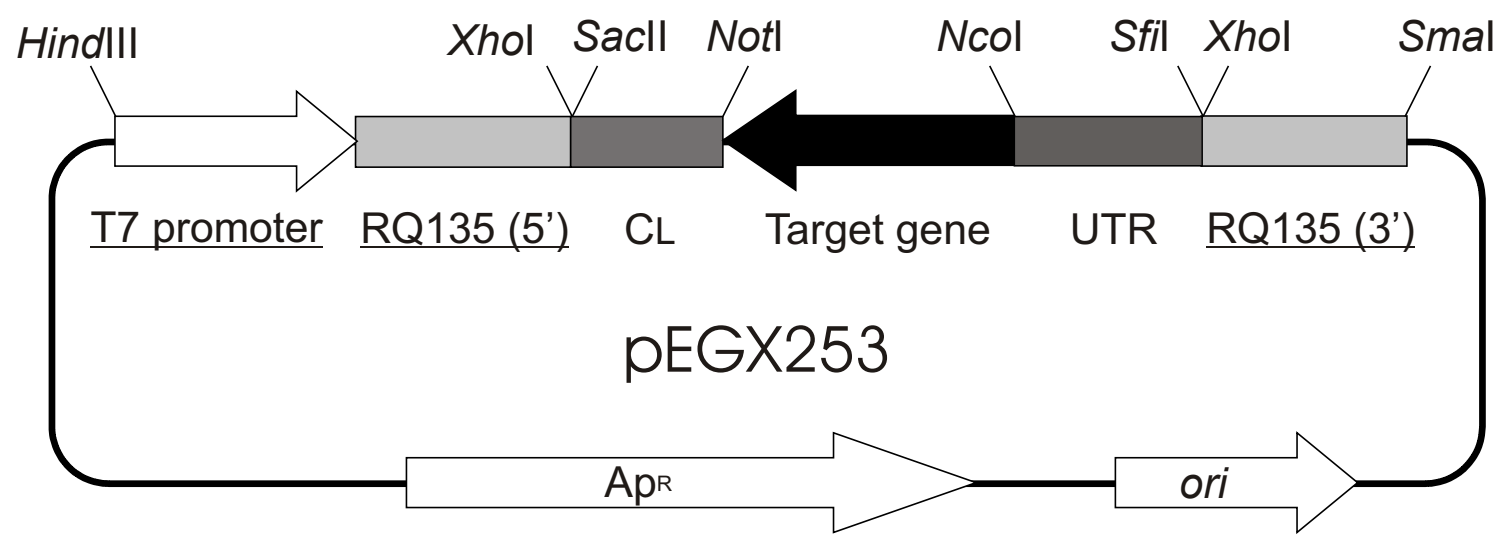

(B)

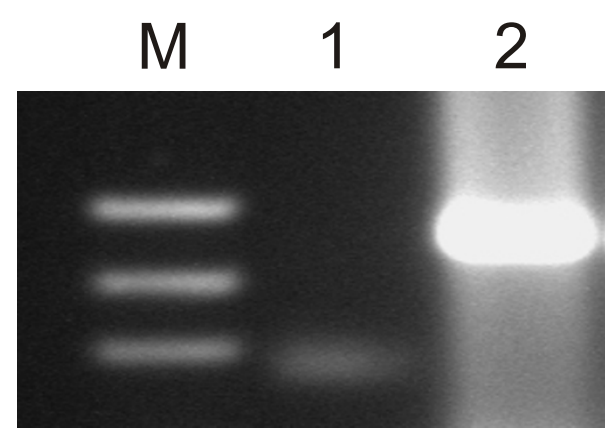

Figure I

$Q \beta$ replicase mutagenesis/ribosome display vector and typical $Q \beta$ replicase amplification reaction. (A): Schematic representation of plasmid pEGX253. Base plasmid PEGX216 (elements depicted with underline) comprised of a MCS site inserted into a modified RQ $135_{-1}(-)$ sequence which was then used to add the required elements to construct $p E G X 253$. Target gene sequence (I2Y-2) was cloned into the Ncol and Notl restriction sites. (B): Product from a typical $Q \beta$ replicase amplification of RGS mRNA. Lane I represents the amount of RGS single-stranded mRNA (-) template added to the Q $\beta$ replicase reaction. Lane 2 shows the $Q \beta$ replicase reaction product following amplification for 2 hrs at $37^{\circ} \mathrm{C}$. Note that $\mathrm{Q} \beta$ replicase amplifies both (-) and the newly generated (+) strands of the RNA eventually leading to a dsRNA product.

denatured and shunted directly into ribosome display. Note that the 5'-UTR, the Kozak sequence, the target gene, and the $\mathrm{C}_{\mathrm{L}}$ region were cloned in the reverse orientation relative to the $\mathrm{T} 7$ promoter to avoid intrinsic stop codons found in our modified RQ $135_{-1}(-)$ sequence. A prerequisite for ribosome display is that there are no stop codons downstream of the translational start signal. Conse- quently, the target gene sequence, the CL tether, and the downstream segment of our modified RQ sequence (which also forms part of the final tether) could not include a translational stop codon. However, stop codons are found in all three frames of the 3' segment of the RQ $135_{-1}(-)$ sequence but in only two frames of the 5 ' segment. By cloning into the appropriate frame in the reverse 
orientation relative to the RQ sequence, stop codons were avoided down stream of the translational start codon. $\mathrm{Q} \beta$ replicase amplifies RNA in both directions, using both the $(+)$ and (-) RNA strands as templates, consequently, mRNA in the correct orientation for translation and ribosome display was innately generated following $\mathrm{Q} \beta$ replicase mutagenesis (Figure 2). Note that due to the replication of both (+) and (-) RNA strands, replication of the starting template would be expected to be limited to one round of replication that would stall when inert RNA duplexes are eventually formed by annealed (+) and (-) strands. However, the RQ $135_{-1}(-)$ sequence contains highly developed secondary structures that have been postulated to prevent complementary (+) and (-) strands of RNA from annealing to each other during replication leading to efficient and very rapid replication $[19,20]$. This property also appears to be important with respect to translation. Ugarov and collegues [17] found that the expression of mRNAs in cell-free translation systems was greatly enhanced as a result of their insertion into RQ135 RNA, again partly attributed to the very stable tertiary structure of the RQ135 RNA. We have found that Q $\beta$ replicase amplified mRNA, upon heat denaturing (see materials and methods), was a suitable template for translation without the need to further purify and isolate the correct strand for translation.

\section{The mutational spectrum of $\mathrm{Q} \beta$ replicase}

A 500 base pair random gene sequence (RGS) from Escherichia coli was used as a model template to establish the mutational spectrum of $\mathrm{Q} \beta$ replicase and to compare this with the mutational profiles generated by other mutagenesis methods. The 500 bp RDS had a GC content of $53 \%$ and did not contain any unusually long stretches of any particular nucleotide. The RGS was embedded into the RQ $135_{-1}(-)$ sequence via the MCS of pEGX216. The mRNA synthesized from this template was subsequently amplified and mutated with $\mathrm{Q} \beta$ replicase (Figure $1 \mathrm{~B}$ ). The mutated mRNA was converted to CDNA using RT-PCR and cloned. Random clones were selected and sequenced. Under the conditions outlined here, the $\mathrm{Q} \beta$ replicase error rate was approximately 1 substitution in every 700 bases. The data in Figure 3 demonstrates that $\mathrm{Q} \beta$ replicase substituted bases randomly across the target template with no obvious hot spots or clustering around particular sequences. $\mathrm{Q} \beta$ replicase showed an equal preference for inserting $\mathrm{A} / \mathrm{T}$ or $\mathrm{G} / \mathrm{C}$ changes, with minimal bias for transitions over transversions (Figure 4A, 4B).

The background error rate (i.e. the mutation rate without $\mathrm{Q} \beta$ replicase) was measured by sequencing 24,000 basepairs from the control reaction. Only a single point mutation was detected which was consistent with the predicted error rate expected from a combination of Taq DNA polymerase (the highest error rate documented for Taq
DNA polymerase in the literature is in the order of $\sim 2 \times$ $\left.10^{-4}[8]\right)$ and the error rate contributed by reverse transcriptase (Superscript III ${ }^{\mathrm{TM}}$ reverse transcriptase error rate is $\left.3.4 \times 10^{-5}[21]\right)$. Together, Taq DNA polymerase and Superscript III $^{\mathrm{TM}}$ did not significantly contribute to the observed mutation rate seen with $\mathrm{Q} \beta$ replicase which in this example was in the order of $\sim 7 \times 10^{-2}$.

The mutational spectrum of $\mathrm{Q} \beta$ replicase compiled on the RGS was directly compared with three DNA-based protocols traditionally used to randomly mutate DNA and generate variant libraries. Two common protocols of EP-PCR (with and without unbalanced concentrations of dGTP) and Mutazyme ${ }^{\mathrm{R}}$ II DNA polymerase (Mut II), a recent blend of two different error-prone polymerases that is claimed to produce an even, non-biased spread of mutations (Stratagene), were used to mutate the RGS as outlined above. Our analysis showed that EP-PCR exhibited a typical and well documented bias for $A / T$ over $\mathrm{G} / \mathrm{C}$ changes and a strong preference for transitions over transversions $[7,8]$. Both EP-PCR protocols gave similar mutation patterns. Mut II showed a somewhat reduced preference for transitions over transversions but still strongly favored $\mathrm{A} / \mathrm{T}$ changes over $\mathrm{G} / \mathrm{C}$ changes (Figure $4 \mathrm{~A}, 4 \mathrm{~B})$.

Figure 4C further dissects the data into the individual base substitutions generated with each of the methods. All possible base substitutions were recovered with $\mathrm{Q} \beta$ replicase and the frequency of all possible transversion substitutions were generally evenly spread. Mut II tended to favor A/T to T/A transversions with the G/C -> C/G transversion recovered only once within the data set. EP-PCR failed to generate many of the possible transversions and showed a distinct preference for $\mathrm{A}$ or $\mathrm{T}$ changes. All of the methods tended to favor $\mathrm{A} / \mathrm{T}$ to $\mathrm{G} / \mathrm{C}$ transitions over $\mathrm{G} / \mathrm{C}$ to $\mathrm{A} / \mathrm{T}$ transitions, with EP-PCR showing the greatest bias and Q $\beta$ replicase showing the least bias.

\section{Using RNA-based mutagenesis to engineer the specificity of TEM-I $\beta$-lactamase}

As an example of the efficacy of $\mathrm{Q} \beta$ replicase for generating diverse mRNA libraries, and to provide a direct comparison with published reports of protein evolution using other mutagenesis methods, $\mathrm{Q} \beta$ replicase mutagenesis was used to modify the well-characterized TEM-1 $\beta$-lactamase antibiotic resistance protein of E. coli. Although TEM-1 $\beta$-lactamase has broad substrate specificity [22], it can not efficiently hydrolyze the extended-spectrum, third generation cephalosporin, cefotaxime [23]. For instance, when wild-type $\beta$-lactamase is expressed in $E$. coli from the plasmid pUC19, the minimum inhibitory concentration (MIC) for cefotaxime is $0.02 \mathrm{ug} / \mathrm{ml}$. To modify the ability of $\beta$-lactamase to hydrolyze cefotaxime, the protein coding sequence was cloned from the plasmid pUC19 into 


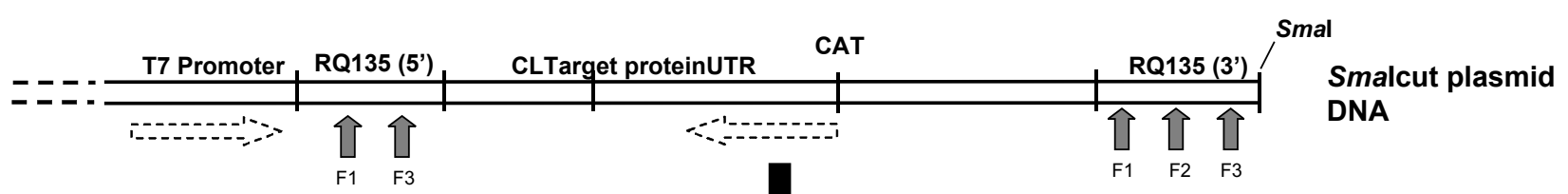

$\widehat{W}=\begin{aligned} & \text { stop codon in } \\ & \text { frame number }\end{aligned}$

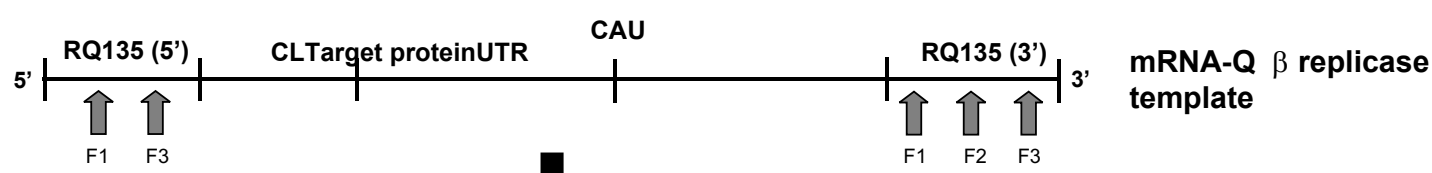

\or feplesese
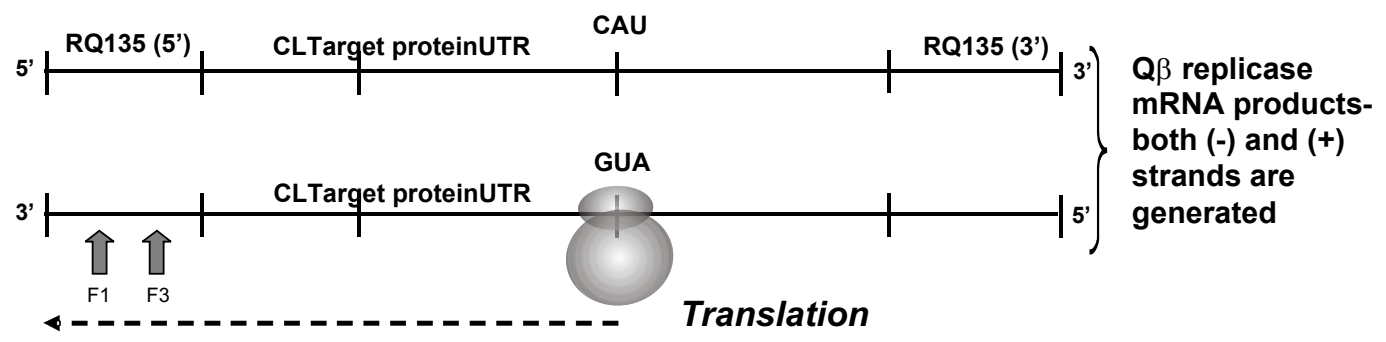

Translate Target protein + CL + RQ135 (5')

in frame 2 for ribosome display to avoid

stopcodonsin the final protein complex

Translation

Figure 2

Coupling $Q \beta$ replicase mutagenesis to ribosome display. The UTR, target gene, and $C_{L}$ region are cloned in the reverse orientation (frame 2) relative to the T7 promoter and the RQ $135_{-1}(-)$ sequence to avoid intrinsic stop codons found in the modified RQ I $35_{-1}(-)$ sequence. Stop codons are found in frames I and 3 of the 5 ' segment and in all 3 frames of the 3 ' segment of the RQ $135_{-1}(-)$ sequence (indicated by grey arrows and the script FI indicating frame I etc.). The absence of stop codons downstream from the translational start signal is an essential requirement of ribosome display. The pathway is as follows; the Smal digested plasmid is used as a template for transcribing mRNA via the T7 promoter sequence. Although the UTR-target gene- $C_{L}$ message is in the reverse orientation and not suitable for translation, the $R Q 135_{-1}(-)$ sequence is in the correct orientation for efficient recognition by $\mathrm{Q} \beta$ replicase. The resulting mRNA becomes the template for $\mathrm{Q} \beta$ replicase. Amplification of this mRNA template with $Q \beta$ replicase generates both (-) and (+) mRNA. The mRNA in the correct orientation for translation is coupled to ribosome display to produce a protein complex (target gene $+C_{L}+R Q I 35-5$ ') that remains tethered to the ribosome due to the absence of a stop codon.

pEGX216, transcribed to synthesize mRNA, and the mRNA was then mutated with $Q \beta$ replicase. The mutated mRNA was converted to cDNA using reverse transcriptase, cloned into a modified pUC19 plasmid (from which the wild-type TEM-1 gene had previously been deleted downstream of the original pUC19 wild-type TEM-1 promoter sequence) and transformed into E. coli. Clones were selected for growth on agar plates containing increasing concentrations of cefotaxime.

Resistant colonies chosen after the first round of mutagenesis and selection had a MIC of $20 \mathrm{ug} / \mathrm{ml}$ (i.e. growth on plates containing $20 \mathrm{ug} / \mathrm{ml}$ cefotaxime) indicating a 1000fold increase in cefotaxime resistance. Ten clones in total were sequenced yielding five variants. All clones carried the G238S amino acid substitution with 2 clones showing no other mutations. Five clones carried two mutations; E104K and G238S (both G->A transitions). The remaining 3 clones carried the G238S mutation in combination with either F22S (A->G), H153R (A->G) or S267G (T->C). These five variants were used as the basis for the next round of mutagenesis and selection. The mRNA that was generated from each of the variants was mixed together in equal proportions and taken through a second round of mutagenesis and selection as outlined previously with round one. Resistant clones from the second round had a MIC of at least $200 \mathrm{ug} / \mathrm{ml}$ (the highest concentration of cefotaxime tested) constituting a minimum 10,000-fold increase in cefotaxime resistance. Again, ten clones were sequenced with all clones carrying in combination with the round 1 mutations E104K and G238S, an extra mutation, M182T (T->C transition) with no silent or other 


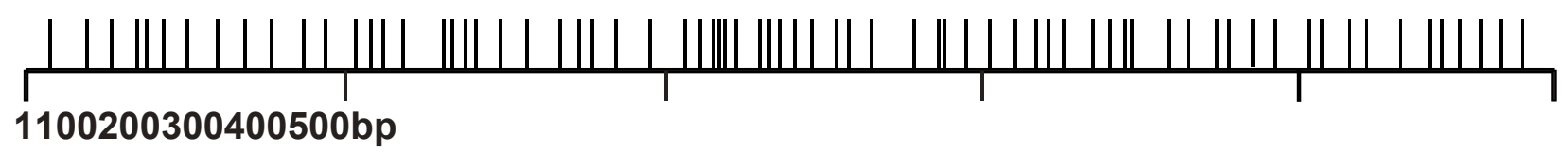

RGS DNA length (1-500 nucleotides)

\section{Figure 3}

Distribution of point mutations along the $\mathbf{5 0 0}$ bp RGS. The spread of $Q \beta$ replicase generated mutations along the length of the RGS indicated that $Q \beta$ replicase substituted bases randomly across the full length of the RGS mRNA template with no obvious mutational hot-spots. A total of 4 I,280 bases were sequenced and all point mutations identified were plotted.

mutations. These three mutations have been described in previous studies of $\beta$-lactamase evolution [23]. Interesting to note that two of the key amino acid mutations resulted from G->A substitutions which would be well represented in a $\mathrm{Q} \beta$ replicase generated library ( $\sim 30 \%$ of total mutations) and less frequent with error-prone PCR ( $11 \%$ of the total mutations) or Mut II ( $\sim 20 \%$ of the total mutations).

Note that control experiments performed with mRNA treated in an identical fashion to that described above, however, not mutated with $\mathrm{Q} \beta$ replicase, did not yield any cefotaxime resistant variants at the concentrations of cefotaxime used for selection.

\section{Coupling RNA-based mutagenesis to ribosome display}

$\mathrm{Q} \beta$ replicase-generated mRNA libraries were directly coupled to ribosome display and used to successfully affinity mature a number of small protein ligands (a single example is presented here with the details of the others to be published elsewhere). Described here is the affinity optimization of a $V_{\text {NAR }}$ that is based on the antibody-like Ig new antigen receptor unique to sharks [24]. These single domain antibody-like fragments have been reported to bind to their targets via a single, long, finger like loop (analogous to CDR3 of antibodies). A $\mathrm{V}_{\mathrm{NAR}}$ II family member, $12 \mathrm{Y}-2$, originally isolated by Nuttall and coworkers [25], binds to AMA-1, a single, trans-membrane domain protein that is thought to be essential for binding and penetration of the Plasmodium falciparum (malaria) parasite (merozoite) into red blood cells [26]. Peptides that bind to AMA-1 have been shown to prevent merozoite invasion [27] suggesting that AMA-1 binders such as $12 \mathrm{Y}-2$ may be biologically useful tools. 12Y-2, however, has only a modest affinity for AMA-1 in the order of 358 $\mathrm{nM}\left(\mathrm{K}_{\mathrm{D}}\right)$ making it an ideal candidate for affinity maturation.

The protein-coding sequence of $12 \mathrm{Y}-2$ was cloned into the mutagenesis/ribosome display plasmid pEGX253, transcribed to synthesize mRNA, and the mRNA subsequently mutated with $\mathrm{Q} \beta$ replicase. The mutated mRNA was used directly in ribosome display. One round of selection via ribosome display was performed; the mRNA was recovered and cloned into an expression vector and transformed into E. coli. A total of 200 clones were analyzed for binding to AMA- 1 by ELISA. A range of variants with affinity increases in the order of 3-7-fold were recovered. One of these clones contained a single mutation K61R (T->A transversion) mapping to framework region 3. This variant was subjected to a second round of $\mathrm{Q} \beta$ replicase mutagenesis and selection via ribosome display, and again, a total of 200 round 2 clones were analyzed. The best variant identified after this second round (clone 1A-13) had a 22-fold increase in binding affinity ( $\mathrm{a} \mathrm{K}_{\mathrm{D}}$ of $16 \mathrm{nM}$ ) compared with the $12 \mathrm{Y}-2$ parent molecule with an approximate 2-fold increase in the association rate and a 13-fold increase in the dissociation rate [28]). 1A-13 contained two mutations; the parent K61R mutation (isolated in the first round) and P90L (resulting from a C->T transition) generated in the second round. The P90L mutation has also been recently described by Nuttall and co-workers [25] and maps to the CDR3-like region. Western blot analysis and gel filtration chromatography indicated that the expression and monomeric state of 1A-13 appeared unchanged from the starting $12 \mathrm{Y}-2$ parent (data not shown).

\section{Discussion}

In this report, we have outlined an RNA mutagenesis method that was specifically developed to provide an improved approach for the in vitro evolution of proteins, in particular, as an effective tool that can be coupled to ribosome display. The RNA-based method is as simple and convenient as PCR to perform and generates a close to ideal random mutational spectrum. Further, $\mathrm{Q} \beta$ replicase is not only error prone, but also highly processive and productive [29] with reactions containing $1 \mathrm{ng}$ of recombinant template mRNA yielding over $1 \mu \mathrm{g}$ of doublestranded RNA product in 30 minutes. Consequently, amplification and mutation can be achieved rapidly in a single step. 
(A)

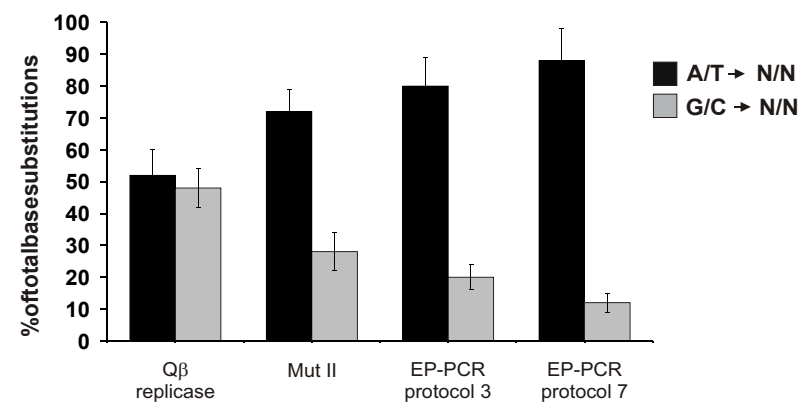

(B)

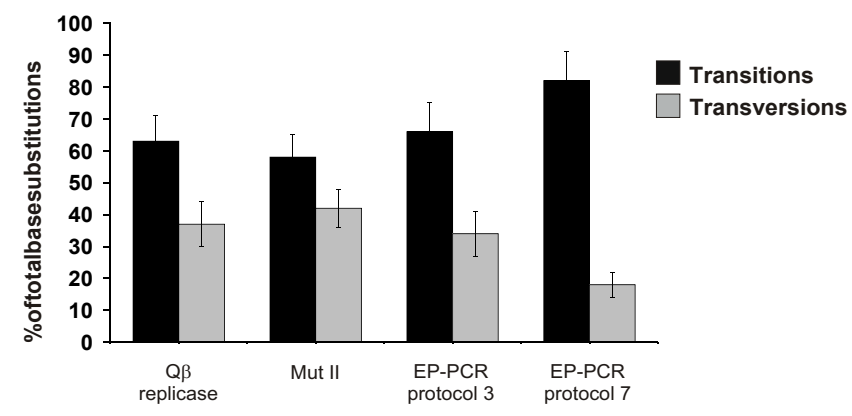

(C)

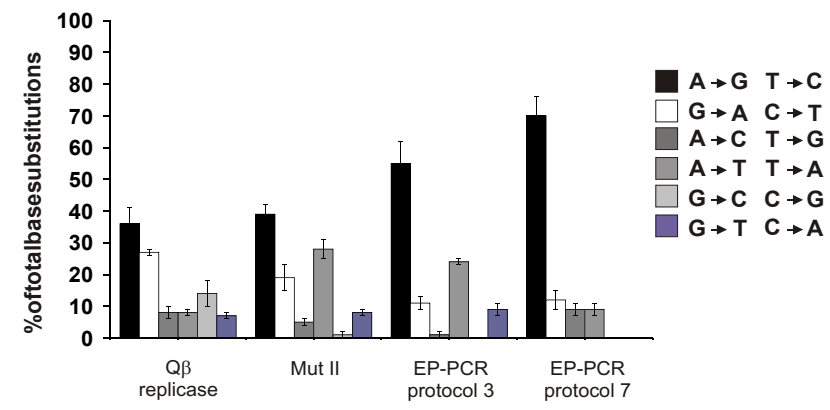

\section{Figure 4}

The mutational spectrum of $\mathbf{Q} \beta$ replicase, Mut II, and EP.PCR. (A): $Q \beta$ replicase did not have significant bias for $A / T$ $>\mathrm{N} / \mathrm{N}$ (black bars) or G/C->N/N (grey bars) changes. Mut II and EP-PCR using either $\mathrm{Mn}^{2+}$ (manufacture's protocol 3) or Mn²+ with an unbalanced dGTP concentration (manufacture's protocol 7) demonstrated significant A/T->N/N bias. (B): The different transition/transversion ratios between the methods. $Q \beta$ replicase and Mut II did not show a significant bias for transitions (black bars) over transversions (grey bars) compared to both versions of EP-PCR, which showed a significant preference for transitions. (C): The percentage of all possible base substitutions for each of the mutagenesis methods analyzed. All possible base substitutions were recovered with $Q \beta$ replicase. The G/C -> C/G transversion was only recovered once with Mut II, which also over represented A/T-> T/A transversions. With EP-PCR (manufacture's protocol 3) A/T-> T/A transversions were over represented, the $A / T->C / G$ transversion was only recovered once and the $G / C->C / G$ transversion was not recovered. G/C -> C/G and G/C->T/A transversions were not recovered with EP-PCR (manufacture's protocol 7). Both versions of EP$P C R$ over represented $A / T->G / C$ transitions. Experiments were repeated 2 times with the standard deviation between experiments shown as error bars. The data set used to generate Figure 3 was as follows: 71 point mutations were characterized for $\mathrm{Q} \beta$ replicase $(52,327$ bases were sequenced in total with an average mutation rate of I point mutation every 737 bases giving a mutation frequency of I.35). 48 point mutations were characterized for Mut II (6720 bases were sequenced in total with a mutation rate of I/I40 bases giving a mutation frequency of 7.I4). EP-PCR manufacture's protocol 3; 74 point mutations were characterized $(36,960$ bases were sequenced in total with a mutation rate of $1 / 499$ bases and a mutation frequency of 2.00$)$ and manufacture's protocol $7 ; 43$ point mutations were characterized $(9,600$ bases were sequenced in total with a mutation rate of I/225 bases giving a mutation frequency of 4.48 ). 
As a practical demonstration of the effectiveness of the mRNA libraries generated with $\mathrm{Q} \beta$ replicase, we used the method to alter the substrate specificity of $\beta$-lactamase. Several other groups have evolved $\beta$-lactamase using a variety of mutagenesis approaches in an attempt to increase the ability of the enzyme to hydrolyze cefotaxime. These studies serve as a solid basis for the evaluation of the data presented here. A comparison is reasonably straight forward as the downstream selection for improved cefotaxime resistance is based on a simple functional assay for growth on an agar plate in the presence of increasing concentrations of cefotaxime, which is expected to be equivalent between laboratories.

As noted above, the cefotaxime MIC for E. coli carrying a wild-type $\beta$-lactamase plasmid is typically around 0.02 $\mathrm{ug} / \mathrm{ml}$. In one of the early examples of $\beta$-lactamase protein engineering, Palzkill \& Botstein [23] used cassette mutagenesis to isolate variants with a maximum MIC of 0.64 $\mathrm{ug} / \mathrm{ml}$. Later, Stemmer [30] used three rounds of DNA shuffling and 2 rounds of back-crossing to yield a TEM-1 variant with an MIC of $640 \mathrm{ug} / \mathrm{ml}$. This cefotaxime resistant mutant contained six amino acid changes (including E104K, G238S and M182T) and an engineered promoter mutation located between the -35 and -10 sites of the $\beta$ lactamase $P 3$ promoter that increased $\beta$-lactamase expression levels by $2-3$-fold. Finally, Zaccolo and Gherardi [31] isolated TEM-1 $\beta$-lactamase variants with activity against cefotaxime that was reported to be 20,000-fold higher ( $\sim 400 \mathrm{ug} / \mathrm{ml}$ ) than wild-type TEM-1 by screening small pools of hyper-mutated clones $\left(<1.5 \times 10^{5}\right)$ from libraries containing up to 27 nucleotide substitutions per gene. Zaccolo and Gherardi [31] required 3 rounds of mutagenesis and selection to isolate clones containing the mutations E104K, G238S and M182T, 2 silent mutations, and a mutation in the pBR322 promoter region. We presume that our second round clones isolated in this study were comparable to the highly resistant Zaccolo and Gherardi clone since the same amino acid substitutions were selected in both studies (notwithstanding the promoter mutation and the copy number difference between the pBR322 plasmid used by Zaccolo and Gherardi and the pUC19 plasmid used in this study). Interesting to note that the unselected TEM-1 libraries of Zaccolo and Gherardi contained a mean mutation frequency of 8.2 and 27.2 substitutions per gene length, however, clones selected on the basis of cefotaxine resisitance showed only 1-11 mutations at the DNA level. It is clear that although increasing the mutation rate allowed a greater diversity to be sampled, it was from the sequences that carried the least number of mutations that functional variants were isolated [10].

This report highlights the efficiency of the $\mathrm{Q} \beta$ replicase RNA methodology. Comparable cefotaxime resistant var- iants were selected relatively quickly (only two rounds of mutagenesis and selection) and with no silent or other superfluous mutations, an approach that was accomplished through what we have termed a "minimal mutational pathway". This approach is based on the premise that a small number of key amino acid substitutions at crucial positions can have a dramatic effect on the properties of the protein. This type of strategy can only be successfully applied when a low, unbiased mutation frequency is used to generate a large number of extremely diverse variants that allow for complete sampling of the immediate sequence space neighborhood. Moore and Maranas [9] noted that base substitution bias introduced by Taq DNA polymerase under error-prone conditions would render some variants more likely than others, effectively reducing the overall library diversity. Patrick and coworkers hypothesised [10] that given that directed evolution is most likely to identify an improved variant when a library is maximally diverse, this would certainly be the case when all variants in a library are equally probable.

The minimal mutational pathway also provides a number of other significant advantages. Due to the relatively low mutation rate, variants have few, if any superfluous or silent base changes, ensuring that a significant fraction of the variant pool being screened is functional. By minimizing the introduction of unnecessary amino acid changes, the method also avoids collateral damage to proteins. Unnecessary amino acid substitutions can have significant negative effects on a target protein including increased immunogenicity [32-34], a reduction in expression level and protein stability [35], amongst others. In particular, altering the immunogenicity status of a protein can have a significant downstream impact on the effectiveness of a product as a potential therapeutic [36].

Without doubt, one of the significant advantages of a RNA-based mutagenesis strategy is the potential to convey variant mRNA libraries directly into selection approaches such as ribosome display with little intervention, therefore maintaining maximum library diversity during the selection process. The effectiveness of $\mathrm{Q} \beta$ replicase-generated mRNA libraries coupled to ribosome display was demonstrated by affinity maturing $12 \mathrm{Y}-2$. Two discrete rounds of $\mathrm{Q} \beta$ replicase mutagenesis and ribosome display yielded the 1A-13 mutant that showed a 22-fold increase in binding to AMA-1 relative to the $12 \mathrm{Y}-2$ parent molecule. 12Y-2 has also been affinity-matured by Nuttall and colleagues [25] using EP-PCR and 3 rounds of selection via phage display. This group isolated several mutants of $12 \mathrm{Y}-2$ with the best of these variants carrying the P90L mutation and showing an 8-fold enhanced affinity for AMA-1. 
Apart from demonstrating the relative efficiency of the $\mathrm{Q} \beta$ replicase mutagenesis approach, the $1 \mathrm{~A}-13$ example is also highlighted here to illustrate the potential difficulties that challenge directed antibody or protein engineering strategies that focus mutagenesis on predicted target contact regions alone. The structure of $12 \mathrm{Y}-2$ has recently been published and the authors suggest that the binding of $12 \mathrm{Y}-2$ is essentially mediated via the relatively long CDR3-equivalent loop $[37,38]$. While amino acid 90 falls within the expected attachment region in this loop, the K61R mutation is situated along the exposed flank of the $\mathrm{V}_{\mathrm{NAR}}$, apparently outside the antigen-binding paratope. Our finding suggests that the K61R mutation may either rotate or flex CDR3 and improve the interaction of CDR3 with AMA-1 or that this distal exposed site may in fact have a significant functional role in the binding interaction by making contact with peripheral remote locations on AMA-1 relative to the epitope targeted by CDR3 [28]. Potentially, the K61R mutation may fall within an additional hyper-variable region that forms a belt around the periphery of the molecule [39]. This additional hyper-variable region may be an important consideration when engineering the affinity of IgNARs in general. Certainly, a directed protein engineering approach exclusively targeting the extended CDR3 loop would not have identified the $1 \mathrm{~A}-13$ variant.

\section{Conclusion}

The success of the minimal mutation pathway approach to protein optimization presented here may be pertinent in light of the debate in the literature over the benefits of exploiting large random libraries created at a low mutation frequency versus smaller libraries manufactured using saturation mutagenesis [31]. Our data suggests that the nature and diversity of mutations generated within a gene library governs the outcome, and not the mutation frequency per se- the wider the spectrum of single amino acid variations that are generated along the gene length (achieved through unbiased nucleotide substitutions), which can then be sampled from a library, the more likely that the best possible amino acid changes required for improving protein properties will be identified. The practical implications of our results are that suitable improved protein candidates generated through in vitro protein optimization technologies can be selected using significantly fewer rounds of mutagenesis and selection, and with little or no collateral damage to the protein or its mRNA.

\section{Methods}

\section{Plasmid construction}

A multi-cloning site comprising of XhoI, SacII, NotI, NcoI, $S f i I$ and XhoI was inserted into a highly modified RQ 135. ${ }_{1}(-)$ sequence $[16,17]$ essentially dividing RQ $135_{-1}(-)$ into a 5 ' end and a 3 ' end with the multi-cloning site buried in the middle of the sequence. PCR was used to add a HindIII site and T7 promoter region to the 5 ' end, and a SmaI site to the 3 ' terminus of the RQ $135_{-1}(-)$ sequence. The construct was inserted into the HindIII and SmaI sites of pUC18 (New England Biolabs). This plasmid was designated pEGX216. The following elements were added to pEGX216 to construct pEGX253, which was used to generate mRNA for $\mathrm{Q} \beta$ replicase mutagenesis and subsequent ribosome display. A 510 base-pair 5'-UTR followed by a complete Kozak sequence was added via the SfiI and NcoI sites; the target gene (in this case, the 12Y-2 coding sequence) was inserted between the NcoI (also serving as the start codon) and NotI sites; and directly downstream of the target gene (between the NotI and SacII sites) was inserted a 316 bp fragment of the mouse antibody constant light chain $\left(\mathrm{C}_{\mathrm{L}}\right)$ devoid of stop codons that served to link the newly synthesized protein to the ribosome complex during ribosome display.

\section{Generating RNA template suitable for $\mathbf{Q} \beta$ replicase}

To generate an mRNA template suitable for $\mathrm{Q} \beta$ replicase, plasmids (either pEGX216 or pEGX253) were linearized with SmaI to generate a blunt end fragment that terminates with CCC at the $3^{\prime}$ end of the RQ $135_{-1}(-)$ sequence. As T7 polymerase initiates transcription with GGG, the resulting mRNA transcripts contained both the 5'-GGG and 3'-CCC termini thought to be essential elements for template recognition by Q $\beta$-replicase [19]. T7 polymerase often inserts a terminal A nucleotide to the 3' CCC sequence, however, this did not appear to significantly influence RNA template recognition. Run off transcription on the linear DNA template was performed by adding $40 \mathrm{mM}$ Tris- $\mathrm{HCl}$ ( $\mathrm{pH}$ 7.9), $6 \mathrm{mM} \mathrm{MgCl}, 2 \mathrm{mM}$ spermidine, $10 \mathrm{mM}$ dithiothreitol, $1 \mathrm{mM}$ each of rCTP, rUTP, rGTP, and rATP, 2 U RNase inhibitor (Promega), 20 U T7 polymerase (Promega) to $200 \mathrm{ng}$ DNA template and incubating at $37^{\circ} \mathrm{C}$ overnight. RNA was DNase-treated to remove the DNA template (RQ1 DNase, Promega) and purified (RNeasy, Qiagen) prior to amplification with $\mathrm{Q} \beta$ replicase.

\section{$\mathbf{Q} \beta$ replicase reaction}

$100 \mathrm{ng}$ of mRNA was pre-heated for $2 \mathrm{~min}$ at $95^{\circ} \mathrm{C}$ in a thermocycler and permitted to cool slowly to room temperature. The mRNA was mixed with $40 \mathrm{mM}$ Tris- $\mathrm{HCl}(\mathrm{pH}$ 7.9), $21 \mathrm{mM} \mathrm{MgCl}_{2}, 2 \mathrm{mM}$ spermidine, $10 \mathrm{mM}$ dithiothreitol, $1 \mathrm{mM}$ each of rCTP, rUTP, rGTP, and rATP, $2 \mathrm{U}$ RNase inhibitor (Promega) and $200 \mathrm{nM} Q \beta$ replicase (prepared in house following the method of Moody et al. [40]) and incubated for a minimum of $120 \mathrm{~min}$ at $37^{\circ} \mathrm{C}$. $\mathrm{Q} \beta$ replicase products were visualized by combining $5 \mathrm{ul}$ of the $\mathrm{Q} \beta$ replicase reaction with loading buffer (Invitrogen), and separated via elecrophoresis on $1 \%$ agarose gels containing ethidium bromide. The remaining mRNA was purified (RNeasy; Qiagen) to remove excess $\mathrm{MgCl}_{2}$ prior to ribosome display. 


\section{Determining mutation rates}

The mutation frequency and nucleotide bias of $Q \beta$ replicase was measured using mRNA transcribed from the RGS DNA which was imbedded into the RQ 135_-(-) sequence of pEGX216 using the XhoI restriction sites. The plasmid was linearized with SmaI and was used in a transcription reaction to generate mRNA template suitable for $Q \beta$ replicase. The mRNA template was amplified with $Q \beta$ replicase and subsequently reverse transcribed and PCRamplified (Superscript III ${ }^{\mathrm{TM}}$ RT-PCR; Invitrogen) prior to blunt-end cloning into pPCR-Script Amp SK (+) (Stratagene), transformed into E. coli strain HB2151, and clones chosen at random were sequenced. The control reaction was processed as outlined above, however, the mRNA was not amplified with $\mathrm{Q} \beta$ replicase.

Error-prone PCR (Diversify PCR Random Mutagenesis Kit; Clontech Laboratories) using the manufacture's protocol 3 (containing $320 \mathrm{uM} \mathrm{Mn}^{2+}$ and $40 \mathrm{uM} \mathrm{dGTP)} \mathrm{and}$ protocol 7 (containing $640 \mathrm{uM} \mathrm{Mn}^{2+}$ and an unbalanced dGTP concentration of $120 \mathrm{uM}$ ) and Mut II (GeneMorph II Random Mutagenesis Kit; Stratagene) were used to mutate RGS DNA closely following the protocols outlined by the manufacturers. The total amount of target template for each reaction was $1 \mathrm{ng}$ with reactions adjusted to give approximately a 1000-fold amplification (total yield/temple amount). Mutated DNA was subsequently cloned into pPCR-Script Amp SK(+), and as above, transformed into E. coli, and random clones sequenced. Since it was not possible to differentiate which of the nucleotide pair was misincorportated during $\mathrm{Q} \beta$ replicase amplification and subsequent RT-PCR, all possible nucleotide substitutions were grouped into six complementary categories. The mutation rate was measured from a total of three replicate experiments for each method. The data is presented as mutation frequency (number of nucleotide substitutions per $\mathrm{kb}$ ), with a minimum of 40 base substitutions characterized for each method.

\section{Evolution of $\beta$-lactamase}

The TEM-1 $\beta$-lactamase gene was cloned into pEGX216 via the XhoI restriction sites, mRNA was transcribed via the T7 promoter, and the mRNA subsequently mutated with $\mathrm{Q} \beta$ replicase. One ng (approximately $10^{11}$ molecules) of mutated mRNA was converted to cDNA and amplified using high fidelity RT-PCR and gene specific primers. The entire RT-PCR reaction was purified, restricted with NcoI and NotI and ligated into 25 ng of a modified pUC19 vector (New England Biolabs) to replace the wild-type TEM1 gene. The modified pUC19 vector was constructed by generating NcoI and NotI sites at the terminal ends of the pUC19 wild-type TEM-1 gene sequence by site directed mutagenesis (QuickChange Mutagenesis) to allow the wild-type TEM-1 gene to be deleted (leaving the original upstream regulating sequences intact). $10 \mathrm{ng}$ of the cloned
DNA was used to transform E. coli XL10-Gold cells (Stratagene) with an estimated transformation efficiency $5 \times$ $10^{9}$ colonies per ug pUC19 DNA. The entire transformation mix (potentially representing a library of approximately $10^{7}$ variants) was plated onto solid nutrient media containing cefotaxime (Sigma) concentrations of either 5, 10 or $20 \mathrm{ug} / \mathrm{ml}$. As cefotaxime resistance on solid media is cell-density-dependant, colony numbers were standardized to $300-500$ colonies per plate and grown at $37^{\circ} \mathrm{C}$ for $30 \mathrm{~h}$. Plasmid DNA from resistant clones that grew on the cefotaxime supplemented media was extracted and sequenced. The DNA from the best clones from the first round of mutagenesis and selection were taken through a second round of mutagenesis and selection by digesting the plasmid DNA of the individual clones with NcoI and NotI and ligating back into pEGX216. The plasmids were then mixed in equal proportions to repeat the mutagenesis and selection process. Second round variants were selected on solid nutrient media containing cefotaxime concentrations of either 50, 100 or $200 \mathrm{ug} / \mathrm{ml}$. A control experiment run in parallel was identical with the omission of the $Q \beta$ replicase mutagenesis step.

\section{Ribosome display}

Ribosome display was performed by adding 2 ug of heat denatured $\mathrm{Q} \beta$ replicase mutated mRNA (heated to $75^{\circ} \mathrm{C}$ for $2 \mathrm{~min}$ and then cooled rapidly to $4^{\circ} \mathrm{C}$ ) to a $50 \mathrm{ul}$ rabbit reticulocyte based translation reaction (Flexi rabbit reticulocyte lysate system; Promega) in an RNase-free microfuge tube (Ambion) following the manufacturer's recommendations and allowing translation to proceed for $25 \mathrm{~min}$ at $30^{\circ} \mathrm{C}$ before diluting the translation mix with the addition of RNase-free, biotin-free skim milk (4\% w/v), PBS, and $5 \mathrm{mM} \mathrm{MgCl}_{2}[11,12,41]$. $1 \mathrm{nM}$ biotinylated AMA-1 (biotinylated with EZ-Link ${ }^{\mathrm{TM}}$ Sulfo-NHS-LC-Biotin; Pierce) was added directly to the diluted translation mix in the microfuge tube and rocked on ice for $5 \mathrm{~h}$ prior to the addition of $2000 \mathrm{nM}$ AMA-1. The mix was rocked on ice for a further $2 \mathrm{~h}$. Ribosome complexes that remained attached to the biotinylated AMA-1 were recovered with streptavidin coated magnetic beads (Dynal). Beads were subsequently washed three times each with PBS containing $5 \mathrm{mM} \mathrm{MgCl}_{2}$ and $0.01 \%$ Tween 20 and two times with PBS containing $5 \mathrm{mM} \mathrm{MgCl}_{2}$ before being re-suspended in $40 \mathrm{ul} \mathrm{dH}_{2} \mathrm{O}$ that had been pre-heated to $65^{\circ} \mathrm{C}$ to disrupt the ribosome complexes. The beads were removed and the supernatant was used directly in RT-PCR to recover mRNA using vector specific primers. The RT-PCR product was gel purified (Qiagen), digested with NcoI and NotI and ligated into pGC FLAG/HIS for expression and analysis [42]. The DNA from designated round 1clones that were to be taken into a second round of mutagenesis and selection were ligated into pEGX253 and processed as outlined above with round 1 . Second round panning incorporated increased selection pressure by increasing the incubation 
phase to $16 \mathrm{~h}$ prior to mRNA recovery. Following the second round of mutagenesis and panning, 500 individual clones were again analysed. Bacterial periplasmic expression and analysis (ELISA and biosensor binding) of $12 \mathrm{Y}-$ 2 clones were as outlined previously [23].

\section{Authors' contributions}

GK designed the study, developed the RNA mutagenesis assay, developed the vectors, directed the research group and drafted the manuscript. ELS determined the mutagenesis spectrum of all the mutagenesis methods analysed, AR, RKC, LP-B and GK performed the ribosome display experiments, MAS performed the ELISA assays used to screen the clones originating from ribosome display and the protein expressions and purification of candidate proteins, ASR performed the BIAcore analysis and also protein expressions and purifications, ND and GC synthesized and purified Q $\beta$ replicase, and GC designed the study, helped to draft the manuscript, and also guided the project. All authors read and approved the final manuscript.

\section{Acknowledgements}

We thank Dr. T. W. Dreher and C. K. Biebricher for supplying our early stocks of $Q \beta$ replicase. We thank Dr. M. Foley for supplying AMA-I, Dr. S. D. Nuttall for providing I2Y-2 through the Co-operative Research Center for Vaccines and Dr. R. L. Crombe, Dr. D. S. Wilson and Dr. S. Nock for comments on the manuscript. This work was supported in part through grants from the Australian Government under the START and Biotechnology Innovation Fund schemes.

\section{References}

I. Delagrave S, Murphy DJ: In vitro evolution of proteins for drug development. Assay Drug Dev Technol 2003, I:187-198.

2. Chusacultanachai S, Yuthavong $Y$ : Random mutagenesis strategies for construction of large and diverse clone libraries of mutated DNA fragments. Methods Mol Biol 2004, 270:3 I9-334.

3. Cadwell RC, Joyce GF: Mutagenic PCR. PCR Methods Appl 1994, 3:136-140.

4. Zaccolo M, Williams DM, Brown DM, Gherardi E: An approach to random mutagenesis of DNA using mixtures of triphosphate derivatives of nucleoside analogues. I Mol Biol 1996, 255:589-603.

5. Brakmann S: Discovery of superior enzymes by directed molecular evolution. Chembiochem 200I, 2:865-87I.

6. Jaeger KE, Eggert T, Eipper A, Reetz MT: Directed evolution and the creation of enantioselective biocatalysts. Appl Microbiol Biotechnol 200I, 55:519-530.

7. Shafikhani S, Siegel RA, Ferrari E, Schellenberger V: Generation of large libraries of random mutants in Bacillus subtilis by PCRbased plasmid multimerization. Biotechniques 1997, 23:304-310.

8. Bracho MA, Moya A, Barrio E: Contribution of Taq polymeraseinduced errors to the estimation of RNA virus diversity. J Gen Virol 1998, 79:2921-2928.

9. Moore GL, Maranas CD: Modeling DNA mutation and recombination for directed evolution experiments. J Theor Biol 2000 , 205:483-503.

10. Patrick WM, Firth AE, Blackburn JM: User-friendly algorithms for estimating completeness and diversity in randomized protein-encoding libraries. Protein Eng 2003, 16:45 I-457.

II. Hanes J, Pluckthun A: In vitro selection and evolution of functional proteins by using ribosome display. Proc Natl Acad Sci USA 1997, 94:4937-4942.

12. He M, Taussig MJ: Antibody-ribosome-mRNA (ARM) complexes as efficient selection particles for in vitro display and evolution of antibody combining sites. Nucleic Acids Res 1997, 25:5I32-5I34.

13. He M, Taussig MJ: Ribosome display:cell-free protein display technology. Brief Funct Genomic Proteomic 2002, I:204-2 I 2.

14. Brown D, Gold L: RNA replication by $\mathbf{Q}$ beta replicase: a working model. Proc Natl Acad Sci USA 1996, 93: I I 558-I I 562.

15. Rohde N, Daum H, Biebricher CK: The mutant distribution of an RNA species replicated by $\mathbf{Q}$ beta replicase. J Mol Biol 1995, 249:754-762.

16. Chetverin $A B$, Chetverina HV, Munishkin AV: On the nature of spontaneous RNA synthesis by $\mathbf{Q}$ beta replicase. J Mol Biol 1991, 222:3-9.

17. Ugarov VI, Morozov IYu, Jung GY, Chetverin AB, Spirin AS: Expression and stability of recombinant RQ-mRNAs in cell-free translation systems. FEBS Lett 1994, 34 I: | 3 |- I 34

18. Morozov IYu, Ugarov VI, Chetverin AB, Spirin AS: Synergism in replication and translation of messenger RNA in a cell-free system. Proc Natl Acad Sci USA 1993, 90:9325-9.

19. Munishkin AV, Voronin LA, Ugarov VI, Bondareva LA, Chetverina HV, Chetverin $A B$ : Efficient templates for $\mathbf{Q}$ beta replicase are formed by recombination from heterologous sequences. I Mol Biol I991, 22 I:463-472.

20. Priano C, Kramer FR, Mills DR: Evolution of the RNA coliphages: role of secondary structures during RNA replication. Cold Spring Harbor Symp Quant Biol 1 987, 52:32 I-330.

21. Potter J, Zheng W, Lee J: Thermal stability and cDNA synthesis capability of SuperScript reverse transcriptase. Focus (In-vitrogen) 2003, 25:19-14.

22. Petrosino JF, Palzkill T: Systematic mutagenesis of the active site omega loop of TEM-I beta-lactamase. J Bacteriol I996, I78: |82|-|828.

23. Palzkill $T$, Botstein D: Identification of amino acid substitutions that alter the substrate specificity of TEM-I beta-lactamase. J Bacteriol 1992, I 74:5237-5243.

24. Greenberg AS, Avila D, Hughes M, Hughes A, McKinney EC, Flajnik MF: A new antigen receptor gene family that undergoes rearrangement and extensive somatic diversification in sharks. Nature 1995, 374: I68-173.

25. Nuttall SD, Humberstone KS, Krishnan UV, Carmichael JA, Doughty L, Hattarki M, Coley AM, Casey JL, Anders RF, Foley M, Irving RA Hudson PJ: Selection and affinity maturation of IgNAR variable domains targeting Plasmodium falciparum AMAI. Proteins 2004, 55:187-197.

26. Peterson MG, Marshall VM, Smythe JA, Crewther PE, Lew A, Silva A, Anders RF, Kemp D): Integral membrane protein located in the apical complex of Plasmodium falciparum. Mol Cell Biol 1989 , 9:3 I5I-3I54.

27. Li F, Dluzewski A, Coley AM, Thomas A, Tilley L, Anders RF, Foley $M$ : Phage-displayed peptides bind to the malarial protein apical membrane antigen- $I$ and inhibit the merozoite invasion of host erythrocytes. J Biol Chem 2002, 277:50303-503I0.

28. Kopsidas G, Roberts AS, Coia G, Streltsov VA, Nuttall SD: In vitro improvement of a shark IgNAR antibody by $Q \beta$ replicase mutation and ribosome display mimics in vivo affinity maturation. Immunol Letters in press.

29. Lizardi PM, Kramer FR: Exponential amplification of nucleic acids: new agnostics using DNA polymerases and RNA replicases. Trends Biotechnol 1991, 9:53-58.

30. Stemmer WP: Rapid evolution of a protein in vitro by DNA shuffling. Nature 1994, 70:389-39I.

31. Zaccolo M, Gherardi E: The effect of high-frequencyrandom mutagenesis on in vitro protein evolution: a study on TEM-I beta-lactamase. Mol Biol 1999, 285:775-783.

32. Schellekens H: Immunogenicity of therapeutic proteins: clinical implications and future prospects. Clin Ther 2002, 24: I720-I740.

33. Halim S, Ramsingh Al: A point mutation in VPI of coxsackievirus $B 4$ alters antigenicity. Virology 2000, 269:86-94.

34. Schreurs MW, Kueter EW, Scholten KB, Lemonnier FA, Meijer C], Hooijberg $\mathrm{E}$ : A single amino acid substitution improves the in vivo immunogenicity of the HPVI6: oncoprotein E7(II-20) cytotoxic T Iymphocyte epitope. Vaccine 2005, 23:4005-40 I0.

35. Calloni G, Zoffoli S, Stefani M, Dobson CM, Chiti F: Investigating the effects of mutations on protein aggregation in the cell. Biol Chem 2005, 280: 10607-106।3. 
36. Hwang WY, Foote J: Immunogenicity of engineered antibodies. Methods 2005, 36:3-10.

37. Stanfield RL, Dooley H, Flajnik MF, Wilson IA: Crystalstructure of a shark single-domain antibody $\mathrm{V}$ region in complex with lysozyme. Science 2004, 305:1770-1773.

38. Streltsov VA, Varghese JN, Carmichael JA, Irving RA, Hudson PJ, Nuttall SD: Structural evidence for evolution of shark Ig new antigen receptor variable domain antibodies from a cell-surface receptor. Proc Natl Acad Sci USA 2004, I 0 I: | 2444- I 2449.

39. Diaz M, Stanfield RL, Greenberg AS, Flajnik MF: Structural analysis, selection, and ontogeny of the shark new antigen receptor (IgNAR): identification of a new locus preferentially expressed in early development. Immunogenetics 2002, 54:50I-5I2.

40. Munishkin AV, Voronin LA, Ugarov VI, Bondareva LA, Chetverina HV, Chetverin $A B$ : Efficient templates for $Q$ beta replicase are formed by recombination from heterologous sequences. J Mol Biol I99I, 221:463-472.

4I. Moody MD, Burg JL, Difrancesco R, Lovern D, Stanick W, LinGoerke J, Mahdavi K, Wu Y, Farrell MP: Evolution of host cell RNA into efficient template RNA by $Q$ beta replicase: the origin of RNA in untemplated reactions. Biochemistry 1994, 33:13836-13847.

42. Hanes J, Jermutus L, Schaffitzel C, Pluckthun A: Comparison of Escherichia coli and rabbit reticulocyte ribosome display systems. FEBS Lett 1999, 450:105-II0.

43. Coia G, Pontes-Braz L, Nuttall SD, Hudson PJ, Irving RA: Panning and selection of proteins using ribosome display. J Immunol Methods 200I, 254:19I-197.

Publish with Bio Med Central and every scientist can read your work free of charge

"BioMed Central will be the most significant development for disseminating the results of biomedical research in our lifetime. "

Sir Paul Nurse, Cancer Research UK

Your research papers will be:

- available free of charge to the entire biomedical community

- peer reviewed and published immediately upon acceptance

- cited in PubMed and archived on PubMed Central

- yours - you keep the copyright

Submit your manuscript here:

http://www.biomedcentral.com/info/publishing_adv.asp
BioMedcentral 